\title{
EXPERIMENTAL STUDY OF THE MECHANICAL AND THERMAL BEHAVIOR OF PELLETS PRODUCED FROM OIL PALM BIOMASS BLENDS
}

\author{
ARZOLA N. \\ GÓMEZ A. \\ RINCÓN S.
}

\author{
Department of Mechanical Engineering \\ Research Groups OPTIMUN and BIOT \\ National University of Colombia \\ Bogotá, D.C., Colombia
}

Received: $18 / 09 / 13$

*to whom all correspondence should be addressed:

Accepted: $10 / 12 / 13$

e-mail: slrinconp@unal.edu.co

\begin{abstract}
The production of bio-pellets is an alternative to add value to the residual biomass of the oil palmextraction process. In this work, an experimental study of the pelletising process of oil palm residual biomass blends is presented. An experimental full factorial design that uses as factors the binding agent content, the moisture content and the mass content of palm kernel shell in the biomass blends is performed. The moisture content of the raw biomass material influences remarkably the durability index of the pellets. These results indicate that high moisture contents in biomass hinder the process of extrusion and linking among the oil palm biomass particles. An increase in the palm kernel shell mass fraction in biomass leads to an increase in the pellets apparent density value. The pellets durability index behaviour study leads to the conclusion that the moisture content is the parameter that exerts the major influence. If the moisture content increases, the durability index decreases. Further, no standard bending tests at 3-points on the pellets are made with the purpose of evaluating the mechanical strength of the densified biomass. Additionally, the produced pellets maintain the quality and durability criteria after being carbonised by means of a thermo gravimetric analysis. The best quality characteristics of the pellets were obtained for a raw biomass material with $10 \%$ of moisture content, $4 \%$ of binding agent content and $40 \%$ by mass of palm kernel shell in the overall biomass respectively.
\end{abstract}

KEYWORDS: Biomass pellets, oil palm biomass, binding agent, mechanical properties.

\section{INTRODUCTION}

The total processing costs of energy production from biomass are strong affected by the transport and distribution cost of large amounts of biomass required due to its medium to low energy content (Kumar et al., 2003). Also, for combustion applications biomass has other inconveniencies, such as, a highly complex physical and chemical composition, an elevated moisture content, low density and high heterogeneity. These aspects make the combustion process difficult to control causing negative effects on fuel efficiency (Gil et al., 2010). Densified biomass has drawn attention due to its advantages over raw biomass, expressed in better physical and combustion properties (Obernberger and Thek, 2004). Densification has stimulated significant interest around the world as a technique for utilization of agro and forest residues as an energy source (Bhattacharya, 2002) and pellets/briquettes production has grown rapidly in the last few decades. Furthemore, mechanical densification of biomass into fuel pellets/briquettes has been shown to significantly reduce storage and transportation costs (Mani et al., 2006). Detailed studies describing the pelletizing process, its variables, factors and binder forces involved in the pellet formation have been published by several researchers (Nielsen et al., 2009; Holm et al., 2007). Stelle et al. (2011) studied the effect the compression pressure has on the final density of the pellets, showing that pressures above $250 \mathrm{MPa}$ have weak influence on the raise of the pellet density. On the other hand, Stelle et al. (2011) found that the mechanical integrity of the pellets was better for moisture contents between $5-15 \%$ (w.b.). In Arzola et al. (2012) a study of the palm kernel shell pelleting process is presented. The use of 
molasses as binding agent with a mass content up to $25 \%$, keeping the average particle size less than $1 \mathrm{~mm}$ and the moisture content up to $18.7 \%$ (d.b.) is evaluated during the experiments. The results showed that the pellets quality increase with an increase in pressure. Arzola et al. (2012) also conclude that a high moisture content (above 10.7\%) hinders the linking process among the palm kernel shells particles during extrusion. In the experiments, the attempts of pelletisation of palm kernel shells prepared without the addition of binder agent were not successful. Only when binder agent content was equal or greater than $12 \%$ mechanically stable pellets were obtained.

Waste from the palm oil industry is abundant and can help to meet the primary energy demand (Razuan et al., 2010). In Colombia, during 2012 the palm oil industry generated 1'726.000 ton of residual biomass composed of palm kernel shells, mesocarp fibers and empty fruit bunches (USDA, 2012), which can be used for power and thermal energy generation. Processing the oil palm biomass into a densified fuel through pelletisation will be an economically attractive option for this by-product. However, the research that has been carried out on the utilisation of palm kernel shells for bio-pellet production is limited at this time. The objective of this work is to assess the suitability of the pelletising process of blends of residual biomass of the oil palm extraction process (palm kernel shell and mesocarp fiber). Extensive pelletisation tests were carried out in order to evaluate the physical properties of pellets produced from these raw materials. The variables explored included binding agent content, moisture content and the mass content of palm kernel shell in the overall biomass mixture. Durability index and apparent density are both important properties describing the physical quality of pellets (Temmerman et al., 2006), for that reason, empirical mathematical models for these properties are obtained and best pelletising conditions are found. Finally, thermogravimetric analyses (TGA) are carried out for thermal degradation of the pellets.

\section{EXPERIMENTAL METHODS}

\section{Oil palm biomass}

The palm kernel shells and mesocarp fibers were obtained from agricultural lands in the east region of Colombia in August 2012 and stored for two weeks in the laboratory. The recollecting process was conducted carefully in order to avoid contamination of the samples with other process materials. These shells and fibers came from middle-age plantations that use Colombian standard cultivation processes; its characterisation is shown in Table 1. The water, volatile matter and ash contents were determined according to the DIN standars 51718, 51720 and 51719. The elemental analysis was performed in an automatic elemental analyser Carlo Erba, ref. 1106 and the heating value was measured in a calorimetric pump according DIN 51900.

Table 1. Characterisation of the oil palm shells and fiber used as raw material (Gómez et al., 2008)

\begin{tabular}{ccccccccc}
\hline & \multicolumn{3}{c}{$\begin{array}{c}\text { Elemental analysis } \\
(\%)\end{array}$} & \multicolumn{2}{c}{$\begin{array}{c}\text { Proximate analysis } \\
(\%)\end{array}$} & $\begin{array}{c}\text { Higher heating value } \\
\left(\mathrm{MJ} \mathrm{kg}^{-1}\right)\end{array}$ \\
\hline & $c_{\text {d.a.b }}$ & $h_{\text {d.a.b }}$ & $n_{\text {d.a.b }}$ & $o_{\text {d.a.b }}$ & $w$ & $F_{\text {d.a.b }}$ & $a_{\text {d.b }}$ & $H H V_{\text {d.b }}$ \\
\hline $\begin{array}{c}\text { Palm kernel } \\
\text { shells }\end{array}$ & 52.8 & 5.7 & $<1$ & 40.5 & 11.2 & 79 & 1.4 & 22.2 \\
\hline Mesocarp fibers & 48.7 & 6.3 & $<1$ & 44.4 & 5.2 & 79 & 5.2 & 18.4 \\
\hline $\begin{array}{l}\text { c: carbon content, } h \text { : hydrogen content, } n \text { : nitrogen content, o: oxygen content, } w \text { : water content, } F: \text { volatile } \\
\text { matter content, a: ash content, d.b: dry basis, d.a.b: dry and ash free basis }\end{array}$ \\
\hline
\end{tabular}

\section{Raw material preparation}

The bulk density of the palm kernel shells and mesocarp fibers prior to palletisation was $773 \mathrm{~kg} \mathrm{~m}^{-3}$ and $350 \mathrm{~kg} \mathrm{~m}^{-3}$ respectively. The palm kernel shells were milled until the average particle size was $570 \mu \mathrm{m}$; the mesocarp fibers were cut in pieces of $10 \mathrm{~mm}$ length. These samples were dehydrated in an oven at $95{ }^{\circ} \mathrm{C}$. Once the oil palm shells and fibers were completely dried they were mixed, and molasses as binding agent in fractions of $4 \%, 8 \%$ and $12 \%$ was added (these contents are referred to the final mass of the samples ready to be tested). Afterwards, the samples were adjusted to moisture contents of $10 \%, 14 \%$ and $18 \%$ by adding an appropriate amount of water using a spray bottle and left in a sealed recipient for two days. During storage a mechanical mixing process was carried out at regular time intervals to guarantee the even distribution of the moisture, binding agent, fiber and kernel shell. The final moisture content was verified in each sample. The mass of material employed for each experiment was of $60 \pm 0.1 \mathrm{~g}$. 


\section{Experimental design}

A systematic study was conducted where three factors were varied according to a three level full factorial design. The factors were: moisture content, binding agent content and the mass content of palm kernel shell in the overall biomass blend. Finally, 27 experimental treatments, arranged in three blocks, were obtained. Table 2 shows the experimental design arrangement. An analysis of the results of the full factorial experimental design using a statistical analysis of variance (ANOVA) was performed. The response surfaces and empirical models for the durability index and apparent density were obtained using statistical analysis system software.

Table 2. Experimental design arrangement

\begin{tabular}{|c|c|c|c|c|c|}
\hline $\mathrm{N}$ & Code $^{1}$ & SF $(\%)^{2}$ & $\mathrm{BA}(\%)^{3}$ & W $(\%)^{4}$ & Number of replicates \\
\hline 1 & W10BA04SF40 & 40 & 4 & 10 & 3 \\
\hline 2 & W14BA04SF40 & 40 & 4 & 14 & 3 \\
\hline 3 & W18BA04SF40 & 40 & 4 & 18 & 3 \\
\hline 4 & W10BA08SF40 & 40 & 8 & 10 & 3 \\
\hline 5 & W14BA08SF40 & 40 & 8 & 14 & 3 \\
\hline 6 & W18BA08SF40 & 40 & 8 & 18 & 3 \\
\hline 7 & W10BA12SF40 & 40 & 12 & 10 & 3 \\
\hline 8 & W14BA12SF40 & 40 & 12 & 14 & 3 \\
\hline 9 & W18BA12SF40 & 40 & 12 & 18 & 3 \\
\hline 10 & W10BA04SF50 & 50 & 4 & 10 & 3 \\
\hline 11 & W14BA04SF50 & 50 & 4 & 14 & 3 \\
\hline 12 & W18BA04SF50 & 50 & 4 & 18 & 3 \\
\hline 13 & W10BA08SF50 & 50 & 8 & 10 & 3 \\
\hline 14 & W14BA08SF50 & 50 & 8 & 14 & 3 \\
\hline 15 & W18BA08SF50 & 50 & 8 & 18 & 3 \\
\hline 16 & W10BA12SF50 & 50 & 12 & 10 & 3 \\
\hline 17 & W14BA12SF50 & 50 & 12 & 14 & 3 \\
\hline 18 & W18BA12SF50 & 50 & 12 & 18 & 3 \\
\hline 19 & W10BA04SF60 & 60 & 4 & 10 & 3 \\
\hline 20 & W14BA04SF60 & 60 & 4 & 14 & 3 \\
\hline 21 & W18BA04SF60 & 60 & 4 & 18 & 3 \\
\hline 22 & W10BA08SF60 & 60 & 8 & 10 & 3 \\
\hline 23 & W14BA08SF60 & 60 & 8 & 14 & 3 \\
\hline 24 & W18BA08SF60 & 60 & 8 & 18 & 3 \\
\hline 25 & W10BA12SF60 & 60 & 12 & 10 & 3 \\
\hline 26 & W14BA12SF60 & 60 & 12 & 14 & 3 \\
\hline 27 & W18BA12SF60 & 60 & 12 & 18 & 3 \\
\hline
\end{tabular}

${ }^{1}$ Each sample is labelled in the following way: W [moisture content, \%], BA [binding agent content, \%] and SF [mass content of palm kernel shell, \%]

${ }^{2} \mathrm{SF}$ : mass content of palm kernel shell in the overall biomass (\%)

${ }^{3} \mathrm{BA}$ : binding agent content (\%); ${ }^{4} \mathrm{~W}$ : moisture content (\%)

\section{Pelleting}

The physical quality of pellet may vary depending on the raw material properties and the manufacturing process. The pellets were produced in a lab scale pelletiser unit able to control process parameters shown in Figure 1(a). The facility consists of a tool steel cylindrical pelletisation chamber (155 mm high, with an internal diameter of $43 \mathrm{~mm}$ ) and a ram. The pelletiser unit allows obtaining pellets with a final diameter of $6.35 \pm 0.15 \mathrm{~mm}$ (the diameter of the die holes are $6.0 \mathrm{~mm}$, indicating that pellets expand after discharge from the die). The length of the pellets ranged between $28.6 \mathrm{~mm}$ and $34.8 \mathrm{~mm}$. A known amount $(60 \mathrm{~g})$ of biomass sample was compacted in the pelletiser unit. The biomass and die were heated to $80 \pm 5^{\circ} \mathrm{C}$ in order to make the compacting process easier. The temperature is controlled using a thermocouple connected to a control unit.

Several preliminary pelleting tests were carried out to study the effects of the experimental factors on the pellets apparent density and durability index. Figure 1(b) shows a view of the extrusion of the 
biomass blend through de die. The maximum pelletized pressure is reached rapidly once the material is compressed and begins the process of passage through the extruder die. The pressure is maintained for 5 seconds and after that, the piston is raised. The compression pressure for all the experimental runs was fixed at $100 \mathrm{MPa}$ (maximum value for the pelletiser unit). The pellets were then stored in sealed plastic bottles until further analysis were done.

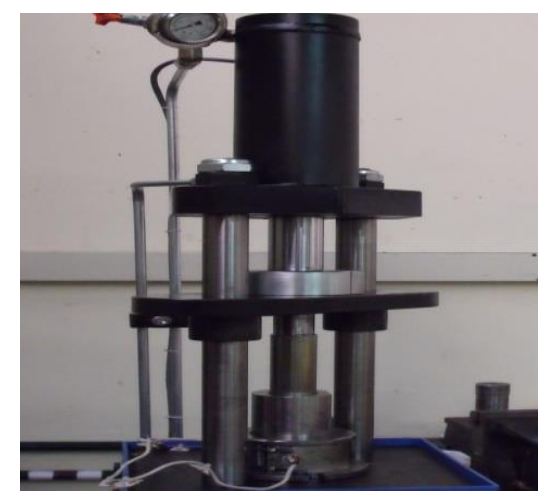

(a)

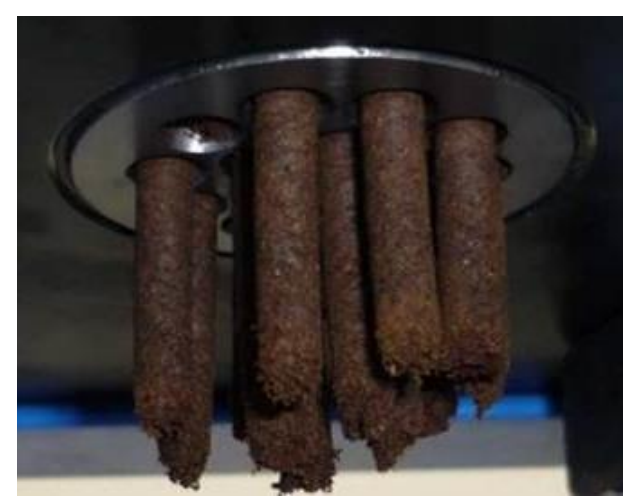

(b)

Figure 1. (a) Oil palm shells pelletiser developed for this series of experiments,

(b) a view of the extrusion of the biomass blend

\section{Pellets apparent density}

The apparent density of the pellets was measured by the indirect method by means of volumetric displacement using a pycnometer and an analytical balance. The effects of binding agent content, moisture content and the mass content of palm kernel shell in the overall biomass on pellet apparent density were analysed using statistical analysis system software.

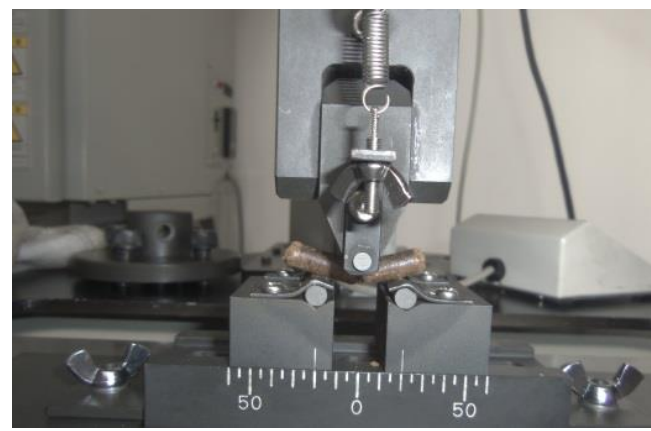

Figure 2. Set up used for a pellet on the bending test machine

\section{Pellets durability index}

Durability is one of the most important physical qualities of pellets. Durability is defined as the ability of pellets to endure destructive forces during handling, transportation and storage. It is measured by the resistance of densified biomass towards shock and friction. Pellets which easily disintegrate produce high ash emissions, boiler feeding system block and increase fire and explosion risk during pellets manipulation, transport and storage (Temmerman et al., 2006). In this study, the durability index was measured for 14 pellets (for each treatment) using a rotating drum (165 mm diameter, 75 $\mathrm{mm}$ width) with a $10 \mathrm{~mm}$ high baffle across the sidewall. After 10 min rotation at $45 \mathrm{rpm}$, the mass of the pieces keeping the circular shape was weighted and compared to the initial mass. This test is based on the concept of the standard method for pellets presented by CEN/TC. The durability index is defined as:

$\mathrm{DI}=\frac{\mathrm{M}_{\mathrm{f}}}{\mathrm{M}_{\mathrm{o}}} \cdot 100 \%$

Where:

DI: durability index (\%). 
$M_{0}$ : initial mass of pellets used in the test $(\mathrm{g})$.

$\mathrm{M}_{\mathrm{f}}$ : remaining mass of pellets used in the test $(\mathrm{g})$.

\section{Bend strength test}

The internal strength of the pellets was analysed by bend strength testing and determined as the force at break. The bend strength is measure using a Shimadzu testing machine fitted with a $50 \mathrm{~N}$ load cell. The test is carried out on three pellets of each treatment of interest. The pellets are tested on 3-points, the two bottom rollers of the machine have a span of $20 \mathrm{~mm}$ between midpoints. The test was run at a compression rate of $20 \mathrm{~mm} \mathrm{~min}^{-1}$, and stopped after pellet failure. Figure 2 shows the set up used for a pellet on the testing machine.

\section{Thermogravimetric analysis}

Thermogravimetric test (TGA) is one of the most commonly used techniques for the thermal characterisation of solid fuels during combustion, gasification and pyrolysis processes (Arenillas et al., 1999). In this study, an available thermogravimetric facility is used to make the thermal analysis during the pyrolysis of the pellets. A standard heating rate of $k=3 \mathrm{~K} \mathrm{~min}^{-1}$ for this type of analysis is used. This experiment allows a preliminary evaluation of the quality, durability and morphological changes of the biomass pellets during thermo-chemical processing.

\section{RESULTS AND DISCUSSION}

Pellets apparent density results

An analysis of the results of the full factorial experimental design using a statistical analysis of variance (ANOVA) was performed. Only the mass content of palm kernel shell in the overall biomass is statistically significant for the apparent density achieved in the pellets for $95 \%$ of probability. Table 3 shows the degree of significance of the coefficients for the factors and their interaction. The expression of the empiric model for the behaviour of the pellets apparent density in function of the mass content of palm kernel shell in the overall biomass blend obtained applying the statistical software from experimental data is:

$\rho_{\mathrm{a}}=2.077-0.0295 \cdot \mathrm{SF}+0.00031 \cdot \mathrm{SF}^{2}$

where:

$\rho_{\mathrm{a}}$ : pellets apparent density $\left(\mathrm{g} \mathrm{cm}^{-3}\right)$.

SF: mass content of palm kernel shell in the overall biomass (\%).

Table 3. ANOVA for estimation of oil palm biomass pellets apparent density

\begin{tabular}{|c|c|}
\hline Source & Value-P \\
\hline SF & 0.0011 \\
\hline BA & 0.4600 \\
\hline W & 0.2618 \\
\hline $\mathrm{SF}^{2}$ & 0.0223 \\
\hline SF.BA & 0.1442 \\
\hline $\mathrm{SF} \cdot \mathrm{W}$ & 0.5925 \\
\hline $\mathrm{BA}^{2}$ & 0.7921 \\
\hline$B A \cdot W$ & 0.9203 \\
\hline$W^{2}$ & 0.3605 \\
\hline
\end{tabular}

SF: mass content of palm kernel shell in the overall biomass (\%)

BA: binding agent content (\%); W: moisture content (\%)

Figure 3 shows the response surface for the apparent density obtained for the pellets. The arrow included in this figure indicates the direction of the fastest increase of the pellets density with the variation in the mass content of palm kernel shell in the biomass blend and the moisture content used. It can be concluded that a high mass content of palm kernel shell in the biomass blend is the unique important factor in determining an increase in the pellet apparent density. 


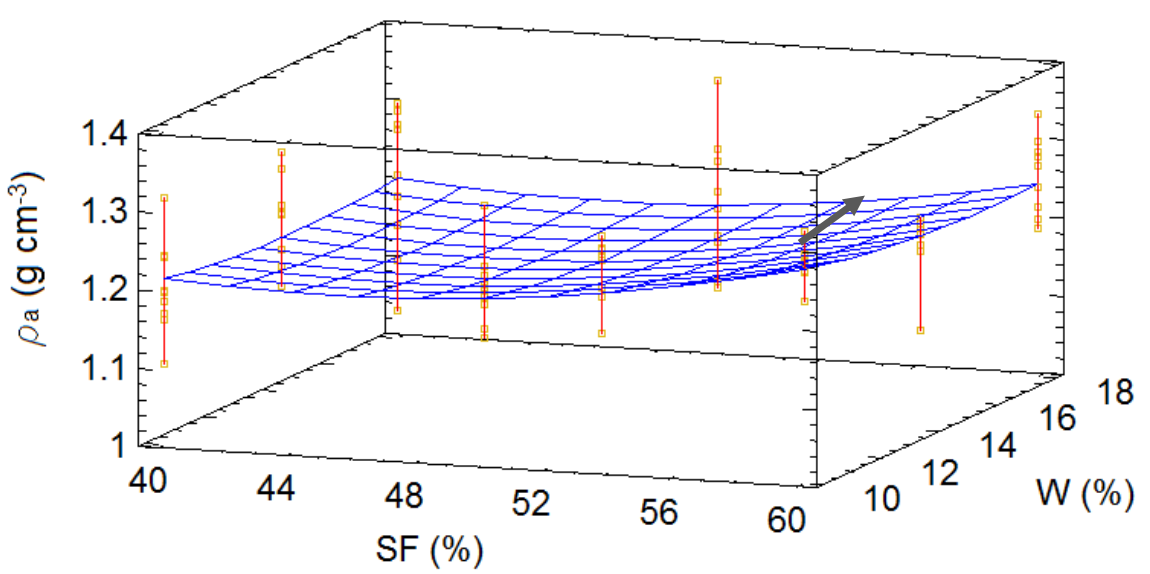

Figure 3. Response surface for oil palm biomass pellets apparent density as a function of the mass content of palm kernel shell and the moisture content $(B A=8 \%)$

(Note: $\rho_{a}$ : pellets apparent density $\left(\mathrm{g} \mathrm{cm}^{-3}\right)$; SF: mass content of palm kernel shell in the overall biomass $(\%)$; W: Moisture content (\%)

\section{Pellets durability index results}

The analysis of the results of the full factorial experimental design was performed using a statistical analysis of variance (ANOVA). It was proved that the experimental factors moisture content and binding agent content are statistically significant for the durability index achieved in the pellets for $95 \%$ of probability. Table 4 shows the degree of significance of the coefficients for the factors and their interaction. The expression of the empiric model for the behaviour of the pellets durability index in function of the experimental factors is:

$\mathrm{DI}=150.3+0.41 \cdot \mathrm{BA}^{2}+4.8 \cdot \mathrm{W}-0.38 \cdot \mathrm{W}^{2}$

where:

DI: pellets durability index (\%)

BA: binding agent content (\%)

W: moisture content (\%)

Table 4. ANOVA for biomass pellets durability index

\begin{tabular}{cc}
\hline Source & Value-P \\
\hline SF & 0.7248 \\
\hline BA & 0.6618 \\
\hline W & $\mathbf{0 . 0 0 0 0}$ \\
\hline SF & 0.5327 \\
\hline SF BA & 0.8771 \\
\hline SF $W$ & 0.7422 \\
\hline BA $^{2}$ & $\mathbf{0 . 0 3 3 0}$ \\
\hline BA W $^{2}$ & 0.1014 \\
\hline
\end{tabular}

SF: mass content of palm kernel shell in the overall biomass (\%)

BA: binding agent content (\%); W: moisture content (\%)

Figure 4 shows the response surface for the durability index obtained in the pellets. The arrow in that figure indicates the direction of the fastest increase of the durability index according to the variation of the moisture content and binding agent content used. 


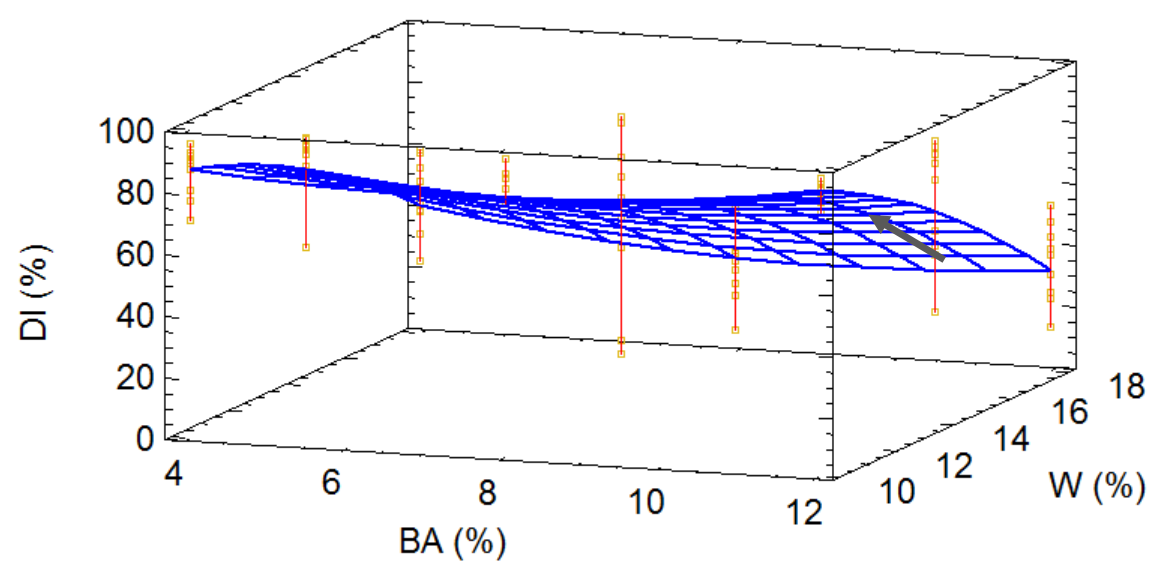

Figure 4. Surface response for oil palm biomass pellets durability index as a function of moisture content and binding agent content $(\mathrm{SF}=50 \%)$

(Note: DI: pellets durability index (\%); BA: binding agent content (\%); W: moisture content (\%)

From the figure can be concluded that the moisture content has a higher influence over the pellets durability index than the binding agent content. The major the moisture content, the minor is the durability index of the pellets. The effect of the binding agent content over the durability index is also statistically significant but it is weak. It can be concluded that the moisture content, is harmful for the pellet quality. On the other hand, the mass content of palm kernel shell in the biomass blends is of marginal importance and it is not a factor of statistical significance for the durability index.

The lower level of moisture content that is appropriate for pellets production lies within the usual moisture content range of the palm kernel shells and mesocarp fibers. That means that no supplementary drying or humidifying process is needed to achieve this moisture condition with the consequent economical advantage. In addition, the binding agent was suitable to guaranty the cohesion between the blended biomass particles.

\section{Bend strength test results}

Bend strength tests were carried out for pellets samples that exhibit the best results for the durability index and apparent density respectively.

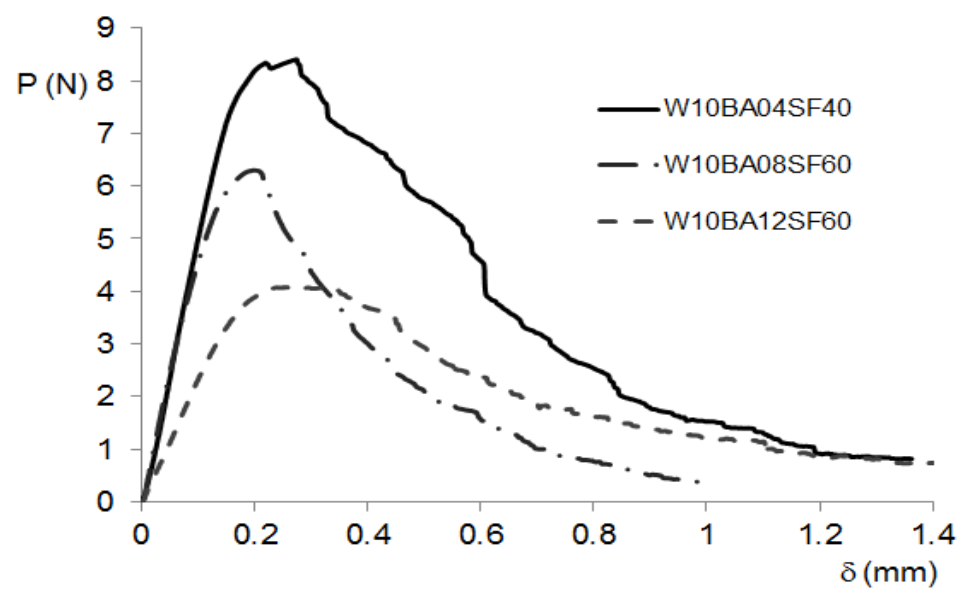

Figure 5. Average curves of load vs. deflection for pellets samples made with three different combinations of experimental factors. The code used for the names of the samples is explained in the footnote of Table 2

Figure 5 shows the average curves of load vs. deflection for representative pellets samples (W10BA04SF40, W10BA08SF60 and W10BA12SF60). From first glance, it is obvious that the pellet bend strength is higher for $4 \%$ of binding agent. The first sample, with $10 \%$ of moisture content, $4 \%$ of binding agent content and $40 \%$ mass content of palm kernel shell, has the highest maximum load value $\left(P_{\max }=8.41 \mathrm{~N}\right)$ and de highest bending stiffness $\left(k_{b}=47.81 \mathrm{~N} \mathrm{~mm}^{-1}\right)$. The other two samples 
have significance lower magnitudes for these mechanical properties. It is concluded that as the binding agent content increases, the pellets' strength and bending stiffness decrease.

\section{Thermogravimetric analysis}

A thermogravimetric analysis is carried out in order to characterise the thermal behaviour of the pellets during thermal degradation or pyrolysis. The experiments are made in an experimental facility that allows the processing of up to $5 \mathrm{~g}$ of biomass (Gómez et al., 2008). Three samples with the same moisture content and different binding agent and mass content of palm kernel shell identified with the codes W10BA04SF40, W10BA08SF60 and W10BA12SF60 are selected as representatives for this analysis. Figure 6 shows the mass variation during pyrolysis of the pellets as a function of time and temperature in the samples.

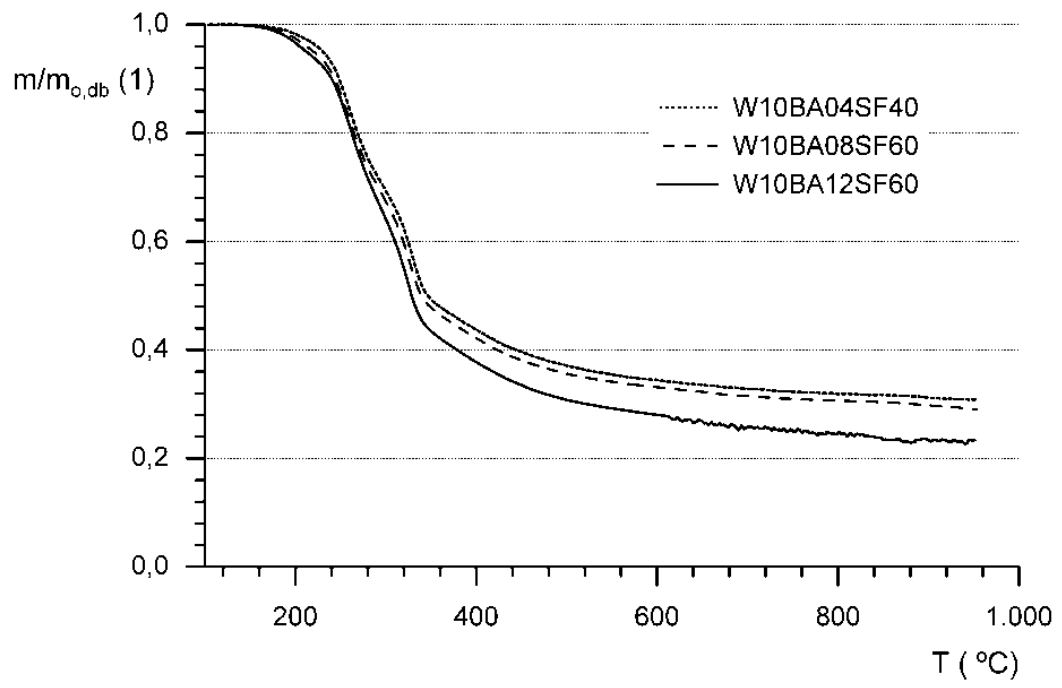

Figure 6. Mass variation curve during pyrolysis of oil palm biomass pellets in a thermogravimetric facility (heating rate $\mathrm{K}=3 \mathrm{~K} \mathrm{~min}^{-1}$; flow of nitrogen as carrier gas $\mathrm{V}_{\mathrm{N} 2}=1.80 \mathrm{I} \mathrm{min}^{-1}$; pyrolysis end temperature $\mathrm{T}=950{ }^{\circ} \mathrm{C}, \mathrm{m}_{0}=$ initial mass). The code used for the names of the samples is explained in the footnote of Table 2

The mass curves show a similar behaviour as that of oil palm shells in their original condition without pelletising (Gómez et al., 2008). By the sample with the highest binding agent content the less char residual is obtained. The pellets suffer a volumetric contraction as it is normal for the thermal degradation processes of biomass. The binding agent content affects strongly the quantity of char obtained after the process. It has to be noted that some longitudinal cracks appear in the carbonised pellets but these remain as such after being processed and maintain similar conditions of durability and quality of that of the original ones. Further studies have to be conducted in order to detail the thermal and combustion characterisation of these pellets.

\section{CONCLUSIONS}

Low moisture content and low to medium binding agent content are, in this order, the most important factors in determining an increase in the durability index and bend strength of the pellets. On the other hand, a high mass content of palm kernel shell in the overall biomass is the most important factor in determining an increase in the pellet apparent density. The produced pellets maintain the quality and durability criteria after being pyrolysed by means of a thermogravimetric analysis. A volumetric contraction of the pellets take place during pyrolysis and some cracks appear in the surface of the solids.

In order to produce high density, high durability and high strength pellets, the biomass blend should have a moisture content of around $10 \%$ and a binding agent content from $4 \%$ to $8 \%$. In particular, one of the best results was obtained for the sample with $10 \%$ of moisture content, $4 \%$ binding agent content and $40 \%$ mass content of palm kernel shell in the overall biomass blend. For this combination of factors, pellets with apparent density of $1.23 \mathrm{~g} \mathrm{~cm}^{-3}$, durability index of $94.6 \%$ and bend strength of $2.1 \mathrm{MPa}$ are obtained. 
The results obtained in this study allow the technical evaluation of the process scale-up at industrial production levels.

\section{ACKNOWLEDGMENT}

The present work was financially supported by the Research Direction Office - DIB (Research Projects DIB-12204 and DIB-14217) of the National University of Colombia in Bogotá - Colombia. The experimental work was carried out at the Thermodynamics and Heat Transfer Laboratory of the Department of Mechanical and Mechatronics Engineering of the National University of Colombia, where the support of the involved students is deeply grateful.

\section{REFERENCES}

Arenillas A., Rubiera F., Pis J.J., Jones J.M. and Williams A. (1999), The effect of the textural properties of bituminous coal chars on NO emissions, Fuel, 78, 1779- 1785.

Arzola N., Gomez A. and Rincón S. (2012), The effects of moisture content, particle size and binding agent content on oil palm shell pellet quality parameters, Ingeniería e Investigación, 32, 24-29.

Bhattacharya S.C. (2002), Biomass energy use and densification in developing countries. Paper presented at the "Pellets 2002: The First World Conference on Pellets", Stockholm, Sweden, 2-4 September.

Gil M.V., Oulego P. Casal M.D., Pevida C., Pis J.J. and Rubiera F. (2010), Mechanical durability and combustion characteristics of pellets from biomass blends, Bioresource Technology, 101, 88598867.

Gómez A., Klose W. and Rincón S. (2008), Biomass pyrolysis: Oil palm shells. Kassel University Press, Kassel.

Holm J.K., Henriksen U.B., Wand K., Hustad J.E. and Posselt D. (2007), Experimental verification of novel pellet model using a single pelleter unit, Energy Fuels, 21, 2446-2449.

Kumar A., Cameron J.B., and Flynn P.C. (2003), Biomass power cost and optimum plant size in Western Canada, Biomass and Bioenergy, 24, 445-464.

Mani S., Sokhansanj S., Bi X. and Turhollow A. (2006), Economics of producing fuel pellets from biomass, Applied Engineering in Agriculture, 22, 421-426.

Nielsen N.P.K., Gardner D.J., Poulsen T. and Felby C. (2009), Importance of temperature, moisture content, and species for the conversion process of wood into fuel pellets, Wood and Fiber Science, 41, 414-425.

Obernberger I. and Thek G. (2004), Physical characteristic and chemical composition of densified biomass fuels with regard to their combustion behaviour, Biomass and Bioenergy, 27, 653-669.

Razuan R., Chen Q., Zhang X., Sharifi V. and Swithenbank J. (2010), Pyrolysis and combustion of oil palm stone and palm kernel cake in fixed-bed reactors, Bioresource Technology, 101, 4622-4629.

Stelle W., Holm J.K., Sanadi A.R., Barsberg S., Ahrenfeldt J. and Henriksen U.B. (2011), Fuel pellets from biomass: The importance of the pelletizing pressure and its dependency on the processing conditions, Fuel, 90, 3825 - 3290.

Temmerman M., Rabier F., Jensen P.D., Hartmann H. and Bohm T. (2006), Comparative study of durability test methods for pellets and briquettes, Biomass and Bioenergy, 30, 964-972.

United States Department of Agriculture - USDA (2012), Oilseeds: World Markets and Trade. 